\title{
An experimental test of a "frustration" theory of reminiscence
}

\author{
C. G. COSTELLO, UNIVERSITY OF CALGARY \\ WILLIAM DISCIPIO, INSTITUTE OF PSYCHIATRY, MAUDSLEY HOSPITAL
}

In line with previous work, high drive Ss under control conditions showed larger reminiscence scores on a pursuitrotor than did low drive Ss. As predicted from a frustration theory of reminiscence, threat of shock for poor performance post-rest resulted in reduced reminiscence scores for high drive Ss. Administration of a placebo did not result in the predicted increase in reminiscence scores for the high drive Ss. The effects of threat of shock or placebo administration on reminiscence scores were not significant for the low drive group.

Though Eysenck (1964a, b) prefers a combined inhibition-consolidation theory to account for all the available data on pursuit-rotor performance, he suggests that reminiscence scores on the pursuit-rotor are ". . .dependent almost purely on consolidation. . ." (Eysenck, 1964b, p. 189).

As predicted by inhibition theory, high drive groups show larger reminiscence scores than do low drive groups (Eysenck \& Maxwell, 1961; Eysenck \& Willett, 1961; Feldman, 1964). But inhibition theory also implies that the PRE-REST performance of high drive groups will be superior to that of low drive groups. This has not been confirmed by the above three studies.

Eysenck has concluded that the data from the studies of the effect of drive level on the pursuit-rotor "... are essentially in conformity with a consolidation hypothesis, provided we are willing to postulate $e$ ither that the duration of the consolidation process is a direct function of drive, or, that the amount of original learning in phase $\mathrm{I}$, 1.e., pre-rest performance later consolidated during rest, is a direct function of drive" (Eysenck, 1964a, p. 179, original italics.)

A direct test of the consolidation theory was reported by Eysenck (1966). The findings confirmed the prediction that practice on a reversed cue (mirror) pursuit-rotor during the rest period, by interfering with the consolidation process, would result in reduced reminiscence scores.

The senior author of the present paper has developed a frustration theory to account for a number of features of pursuit-rotor performance including reminiscence. Briefly, the theory states that frustration may develop during performance on the pursuit-rotor, the degree of frustration being some function of the S's level of motivation. The frustration interferes with both learning and performance of the pursuitrotor task. During the rest period the $S$ recovers to some degree from the frustration, hence the reminiscence effect.

According to the frustration theory, the poor per- formance PRE-REST of low drive Ss is due primarily to their low level of motivation. A rest period will not alter their level of motivation, hence the absence of a reminiscence effect. The poor performance PREREST of the high drive Ss is due primarily to the frustration produced by the failure to keep on target. Since the PRE-REST practice is massed, the $S$ has no opportunity to recover from the frustration. This opportunity is provided by the rest period, hence the reminiscence effect.

With regard to the reduced reminiscence scores produced by practice on a reversed-cue pursuit-rotor during the rest period, the frustration theory would explain this on the grounds that a reversed-cue pursuitrotor would be particularly frustrating and allow no opportunity from the frustration accumulated during PRE-REST performance.

The present paper reports a test of the frustration theory.

\section{Method}

The high drive group consisted of 15 college freshmen majoring in physical education, who were told at the beginning of the experiment that their performance on the pursuit-rotor constituted an important placement exam. The low drive group consisted of 15 college freshmen who were Ss for the experiment as part of their obligations in an introductory psychology course. Each of the two drive groups was divided equally into three subgroups. All of the Ss first of all had $5 \mathrm{~min}$ massed practice on a pursuit-rotor identical to that used by Eysenck (1964c). This was followed by a $5 \mathrm{~min}$ rest period for all the Ss. During the rest period, Ss in Group A had electrodes pasted on their arms and wrists and were told that they would receive a shock if their performance fell below a certain criterion during POST-REST practice. The Ss in Group B were administered a placebo tablet with the instructions that the tablet was a tranquilizer. The Ss of Group C were simply instructed to sit and rest. At the end of the rest period, all the Ss were given a further $5 \mathrm{~min}$ massed practice on the pursuitrotor.

The reminiscence score for $S$ was the total time on target for the first 10 sec POST-REST trial (this 10 sec trial was preceded by 2 sec practice, following Eysenck's method, so that the Ss would not enter the first trial "cold") minus the total time spent on target during the last $10 \mathrm{sec}$ PRE-REST trial.

In line with previous work, the high drive group was expected to show higher reminiscence scores than the low drive group. On the basis of the frustra- 
Table 1

Mean reminiscence scores of six experimental groups

\begin{tabular}{lcc} 
& High Drive & Low Drive \\
\hline $\begin{array}{l}\text { Group A } \\
\text { (shock) }\end{array}$ & 0.50 & 1.25 \\
$\begin{array}{c}\text { Group B } \\
\text { (placebo) } \\
\text { Group C } \\
\text { (control) }\end{array}$ & 2.00 & 1.30 \\
\hline
\end{tabular}

tion theory, it was predicted that within the high drive group: Group A would show smaller reminiscence scores than Group C, since the threat of shock would reduce the degree of recovery from frustration in Group A; Group B would show larger reminiscence scores than Group C, since the placebo administration would result in a greater degree of recovery from frustration.

Similar predictions were made for the subgroups of the low drive group. Since, however, the degree of frustration in the low drive group was assumed to be less than that in the high drive group, differences between the subgroups were expected to be less. Results

The mean reminiscence scores of the six experimental groups are shown in Table 1.

Analysis of variance indicated that neither the main effect of drive nor that of frustration were significant, but the interaction between these two was significant $(F=4.22, d f=2 / 24, p<.05)$. Duncan's (1955) new multiple range test indicated that although the main effect of drive in the analysis of variance was not significant, the difference between the means for the high drive control group and the low drive control group was significant $(p<.01)$ in line with previous work. As predicted, within the high drive group, Group A showed significantly less reminiscence than Group $C$ $(p<.05)$. Contrary to prediction, the difference between the means for Group B and Group C within the high drive group was not significant.

Within the low drive group, none of the differences between the means was significant.

\section{Discussion}

The significantly smaller reminiscence score within the high drive group when the Ss were threatened with shock (Group A) compred with the control Ss (Group C) gives some support for the hypothesis that the threat of shocklessens the degree of recovery from frustration.

Within the high drive group, the Ss administered a placebo (Group B) did not show the predicted larger reminiscence effects than the control Ss (Group C). A plausible explanation for this is that the rest period itself resulted in the Ss almost completely recovering from their frustration. Some support for this suggestion is found when we compare the performance of the high drive control group (Group C) on the first $10 \mathrm{sec}$ trial POST-REST with the performance of a group of Ss after $5 \mathrm{~min}$ of distributed practice. Feldman's (1964) data indicate that a distributed practice group after 5 min practice is on target approximately $44 \%$ of the time. The high drive control group in the present study was on target during the first $10 \mathrm{sec}$ POSTREST trial approximately $46 \%$ of the time.

The lack of significant differences between the means within the low drive group is generally in line with the predicted lesser effect of the experimental manipulations with this group.

It seems clear that we cannot as yet attribute reminiscence on the pursuit-rotor to any one process such as consolidation. As an explanatory concept, recovery from frustration appears to have at least equal status to consolidation.

\section{References}

Duncan, D. B. Multiple range and multiple $F$ tests. Biometrics, $1955,11,1-42$.

Eysenck, H. J. An experimental test of the "inhibition" and "consolidation" theories of reminiscence. Life Sci., 1964a, 4, 175188 .

Eysenck, H. J. Personality and reminiscence-an experimental study of the "reactive inhibition" and the "conditioned inhibition" theories. Life Sci., 1964b, 3, 189-198.

Eysenck, H. J. Experiments in motivation. Oxford: Pergamon Press, 1964c.

Eysenck, H. J. (Unpublished manuscript) 1966.

Eysenck, H. J., \& Maxwell, A. E. Reminiscence as a function of drive. Brit. J. Psychol., 1961, 52, 43-52.

Eysenck, H. J., \& Willett, R. A. The measurement of motivation through the use of objective indices. J. ment. Sci., 1961, 107, $961-968$.

Feldman, M. P. Pursuit rotor performance and reminiscence as a function of drive level. In $\mathrm{H}$. J. Eysenck (Ed.), Experiments in motivation. Oxford: Pergamon Press, 1964. 